\title{
Analyses of non-benzodiazepine-induced adverse events and prognosis in elderly patients based on the Japanese adverse drug event report database
}

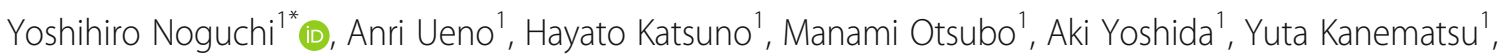
Ikuto Sugita ${ }^{1}$, Tomoya Tachi ${ }^{1}$, Teruo Tsuchiya ${ }^{1,2}$ and Hitomi Teramachi ${ }^{1,3^{*}}$

\begin{abstract}
Background: The contents of the guidelines for the use of non-benzodiazepines (Z-drugs) differ slightly between THE JAPANESE SOCIETY OF SLEEP RESEARCH and THE JAPAN GERIATRIC SOCIETY, and the recommended directions are conflicting. Therefore, we analyzed the use of the Japanese Adverse Drug Event Report database (JADER) for identifying adverse events (AEs) caused by Z-drugs and clarifying their occurrence trend and prognosis.

Methods: The signal value for comparison was calculated by using the proportional reporting ratio (PRR) and chi-squared test $\left(X^{2}\right)$ results of data of elderly and non-elderly patients. Among AEs for which signals were detected in the elderly, we determined that those with lower signal values for non-elderly patients that were half the signal value of the elderly should be used with particular caution in the elderly. We also compared the prognoses.

Results: The AEs with $>1$ risk ratio (RR) in elderly and non-elderly patients were regarded as those that should be noted in the prognosis of AEs in elderly patients. Furthermore, 28 AEs were detected in elderly patients' signals. In this study, in addition to movement disorders such as "falls" and "bone fractures," identified by two academic societies, signal characteristics of the elderly were obtained for psychiatric disorders and eye disorders.

Conclusions: There was no difference in prognosis, but these disorders could reduce the quality of life of patients. Therefore, we consider that in prescribing appropriate drug therapy for insomnia, attention should be paid to the occurrence of the AEs caused by the Z-drugs revealed by this study and the guidelines.
\end{abstract}

Keywords: Japanese adverse drug event report database (JADER), Signal detection, Elderly patients, Non-benzodiazepine (Z-drug)

\section{Background}

Insomnia is defined as the inability to sleep or sleeplessness that lasts for at least 1 month under proper sleeping conditions, and is accompanied by intense daytime fatigue and decreased concentration, energy, drowsiness, and vigor. Recently, in Japan, 20 to $25 \%$ of adults have been reported to experience insomnia $[1,2]$, and its incidence is particularly high in elderly people aged above 60 years [1]. Furthermore, 4 to $6 \%$

\footnotetext{
* Correspondence: noguchiy@gifu-pu.ac.jp; teramachih@gifu-pu.ac.jp ${ }^{1}$ Laboratory of Clinical Pharmacy, Gifu Pharmaceutical University, 1-25-4, Daigakunishi, Gifu 501-1196, Japan

Full list of author information is available at the end of the article
}

of Japanese adults routinely use sleeping pills [2], and the major drugs widely used in clinical practice are benzodiazepines (BZ drugs) and non-benzodiazepines (Z-drugs). These drugs act on benzodiazepine receptors in the brain to exert hypnotic actions by enhancing the action of the gamma-aminobutyric acid (GABA) system, which shows inhibitory action in the central nervous system (CNS). Previously, barbiturates acting on the same GABA receptor were used, but these newer drugs are considered to be less likely to cause fatal damage due to suppression of the respiratory center than barbiturates. However, the doses of $\mathrm{BZ}$ drugs used in Japan are higher than those used

(c) The Author(s). 2018 Open Access This article is distributed under the terms of the Creative Commons Attribution 4.0 International License (http://creativecommons.org/licenses/by/4.0/), which permits unrestricted use, distribution, and reproduction in any medium, provided you give appropriate credit to the original author(s) and the source, provide a link to the Creative Commons license, and indicate if changes were made. The Creative Commons Public Domain Dedication waiver (http://creativecommons.org/publicdomain/zero/1.0/) applies to the data made available in this article, unless otherwise stated. 
overseas. Furthermore, there is also the problem of side effects including anxiolytic actions, motor dysfunction, muscle relaxant action, memory disorders, and long-term use dependency and tolerance.

Therefore, the " Clinical guidelines for proper use of sleeping pills and drug withdrawal" of THE JAPANESE SOCIETY OF SLEEP RESEARCH states that the quality of evidence is "moderate" and the recommendation is "weak," and it recommends the use of Z-drugs for elderly people who experience sleeplessness [3]. Alternatively, the "Guidelines for Medical Treatment and its Safety in the Elderly 2015" of THE JAPAN GERIATRIC SOCIETY indicate that the quality of the evidence is "moderate" and the recommendation degree is "strong." Therefore, long-term use of Z-drug among the elderly is not recommended [3].

Thus, THE JAPANESE SOCIETY OF SLEEP RESEARCH evaluated "the presence or absence of drug use" and THE JAPAN GERIATRIC SOCIETY evaluated the "long-term use of drugs," and although the contents of their guidelines differ, the recommended direction is contradictory [3].

These guidelines are prepared using a method similar to that of the Grading of Recommendations Assessment, Development, and Evaluation (GRADE) system. In determining the recommendation level, there is also the challenge of insufficient documented proof, because the empirical evidence is not a research topic and the evidence is scarce because of the limited data on the elderly. Therefore, repeated discussions and voting by the research groups responsible for preparing guidelines have provided some evidence, which has been included in the guidelines even if it is not adequate [3].

However, the members of the GRADE working group have pointed out that the original method of preparation used by THE JAPAN GERIATRIC SOCIETY did not follow the GRADE system. Specifically, issues were pointed out such as the fact that "evidence is not integrated with outcomes as the main body" and "the evaluation method of the quality of evidence is uncertain" [3]. THE JAPANESE SOCIETY OF SLEEP RESEARCH doubts that the recommendations of THE JAPAN GERIATRIC SOCIETY differ and strongly criticize their methods, indicating that there are problems with document searches [3].

Furthermore, the method used by THE JAPANESE SOCIETY OF SLEEP RESEARCH also points out the following problems by Okumura [3]. These problems include the following: "the collection year of the document is not up to date," "the description of statistical significance is incomprehensible (the confidence interval includes a zero, and there is no statistical significance)," the quality of the evidence including 'the method of evaluation is unclear', and "no document is cited by the integrated primary research, which is not clearly specified [3]."
To use drugs appropriately, it is important to understand the adverse events (AEs) they cause. Signals based on the principle of disproportionality focusing on the difference in the number of reported cases of AEs are used as indicators of the safety of drugs. Signals are considered to be able to detect unknown AEs at an early stage, and numerous risk assessments have been reported [4-8]. These signals include proportional reporting ratio (PRR) [9] and reporting odds ratio (ROR) [10]. There are also signals such as the Bayesian Confidence Propagation Neural Network (BCPNN) [11] and Gamma-Poisson Shrinker (GPS) [12] that use Bayesian estimations. Furthermore, we have also reported the analysis of prognostic comparisons of elderly and nonelderly patients [13].

Therefore, in this study, we used the Japanese Adverse Drug Event Report (JADER) database of a spontaneous reporting system (SRS) in Japan, to identify AEs caused by Z-drugs and analyze their trends.

\section{Methods \\ Data source}

The JADER is a database of post-marketing surveillance and spontaneous reports collected by Pharmaceuticals and Medical Devices Agency (PMDA) as Japanese regulatory authority. This database is used for Japanese pharmacovigilance, and it is similar to the database for FAERS in the United States, and other countries for pharmacovigilance. The JADER database was downloaded from the website of PMDA. It consists of four datasets in csv format: patient demographic information (DEMO.csv), drug information (DRUG.csv), AE information (REAC.csv), and primary disease information (HIST.csv). In this study, data from patients registered in JADER from the first quarter of 2004 to the fourth quarter of 2015 were used. However, reports with missing information on sex, age, or primary disease, and where subjective terms such as "youth" and "elderly" were used, were excluded from the analysis data.

\section{Definitions of suspected drugs and AEs}

The suspected drugs were the Z-drugs zolpidem, eszopiclone, and zopiclone. $\mathrm{AE}$ is registered in the JADER database as the preferred term (PT) of the Medical Dictionary for Regulatory Activities/Japanese version (MedDRA/J). In this study, the target AE was defined as the high-level group term (HLGT).

\section{Definition of elderly patients}

Data on the age of patients in the cases registered in the JADER database are provided as data collected every 10 years in principle for privacy consideration. The definition of elderly and non-elderly patients has ambiguous and subjective parts, and the determination is 
challenging. According to the definition of the United Nations, elderly people are those over 60 years old. The World Health Organization (WHO) defines people over the age of 65 as elderly people, and in numerous countries, those 65 years and older are defined as elderly people. Therefore, in this study, similar to previous reports $[8,13,14]$, we considered elderly patients as those $>60$ years old and non-elderly patients as those $<60$ years.

\section{Comparison of signal values}

Signal values to be compared were calculated from the PRR and chi-squared test $\left(x^{2}\right)$ values of elderly and nonelderly patients, respectively, using formula (1) proposed by Takagi et al. [15]:

$$
\text { Signal value }=\ln (\mathrm{PRR})+\ln \left(\mathrm{X}^{2}\right)
$$

In this study, among the AEs for which signals were detected in the elderly, we determined that those with signal values in non-elderly patients that were lower than half of that in the elderly should be used with particular caution in the elderly using formula (2):

$$
\begin{aligned}
& 1 / 2 \text { (elderly patients' signal value) } \\
& \quad \text {-non-elderly patients' signal value }>0
\end{aligned}
$$

As this signal value cannot be calculated as having 0 reports of AEs, we corrected the value by adding 0.5 (Haldane-Anscombe 1/2 correction) [16].

\section{Prognosis of AEs}

From the registered outcome information, "recovery" and "light" were classified as good prognosis. In contrast, "death," "with sequelae," and "unrecovered" were classified as AEs with poor prognoses. We created a $2 \times 2$ contingency table based on the elderly/non-elderly and good/bad prognosis of classified AEs and calculated the risk ratio (RR), the $95 \%$ confidence interval $(\mathrm{CI})$, and $X^{2}$ value [13]. As 0 cells in the $2 \times 2$ contingency table cannot be the result of the calculation, we corrected this bias by adding 0.5 to all cells (Haldane-Anscombe $1 / 2$ correction) [17].

\section{Results}

We obtained data on 176,184 cases of oral drugs use by patients (elderly and non-elderly patients, 110,126 and 66,058 cases, respectively) excluding cases where information on sex and age were unclear from the analysis data table based on patient background factor. Of the 321 AEs, 28 were detected in elderly patients' signals (Table 1). Among the 28 AEs, the following 12 were particularly determined to require cautious monitoring in the elderly: glaucoma and ocular hypertension ( $\mathrm{n}_{11}: 10$, PRR: 21.3, $x^{2}:$ 152.6, signal value: 8.1), impulse control disorders not elsewhere classified (NEC) $\left(\mathrm{n}_{11}: 6\right.$, PRR: 26.0, $\chi^{2}: 102$. 5 , signal value: 7.9 ), neurological| special senses and psychiatric investigations $\left(\mathrm{n}_{11}: 6\right.$, PRR: 13.4, $\mathrm{x}^{2}: 52.2$, signal value: 6.5$)$, injuries by physical agents $\left(\mathrm{n}_{11}: 7\right.$, PRR: 6.4, $\chi^{2}$ : 25.6, signal value: 5.1$)$, personality disorders and disturbances in behavior $\left(\mathrm{n}_{11}: 5\right.$, PRR: 7.6, $x^{2}: 21.3$, signal value: 5.1), neurological disorders of the eye ( $\mathrm{n}_{11}: 9$, PRR: $4.6, \chi^{2}: 21.3$, signal value: 4.6$)$ , manic and bipolar mood disorders and disturbances $\left(\mathrm{n}_{11}: 3\right.$, PRR: 6.7, $\mathrm{x}^{2}:$ 9.0, signal value: 4.1$)$, movement disorders (include parkinsonism) $\left(\mathrm{n}_{11}: 21\right.$, PRR: 2.7, $X^{2}: 19.9$, signal value: 4.0), enzyme investigations NEC $\left(\mathrm{n}_{11}: 17\right.$, PRR: $2.4, \chi^{2}: 12.4$, signal value: 3.4$)$, disturbances in thinking and perception $\left(\mathrm{n}_{11}: 12\right.$, PRR: $2.5, \mathrm{X}^{2}: 9.1$, signal value: 3.1$)$, vision disorders $\left(\mathrm{n}_{11}: 7\right.$, PRR: 2.6, $x^{2}$ : 5.3, signal value: 2.6), and ocular infections irritations and inflammations $\left(\mathrm{n}_{11}: 8, \mathrm{PRR}\right.$ : 2.4, $x^{2}: 5.0$, signal value: 2.5$)$.

In addition, when these $12 \mathrm{AEs}$ were counted using the System Organ Class (SOC), four and three HLGTs were classified as psychiatric disorders and eye disorders, respectively (Tables 2,3 ).

Among the AEs for which signals were detected in the elderly, none led to poor prognosis in the elderly compared to the non-elderly (Table 4). (Table 4-1: Especially the prognostic comparison of adverse events [AEs] characterized by the elderly. (Table 4-2: Prognostic comparison of other adverse events [AEs]).

\section{Discussion}

"THE JAPANESE SOCIETY OF SLEEP RESEARCH" and "THE JAPAN GERIATRIC SOCIETY" have completely different recommendations on the use of Zdrugs. The GRADE system for preparing guidelines is not a method that guarantees reproducibility but one that increases transparency.

Therefore, the recommendations proposed by independent research teams may differ because of this characteristic. However, these guidelines have become an evaluation of the quality of unclear evidence [3].

Recently, the improvement in information technology has enabled the analyses of numerous large datasets, and it is expected that accurate evidence could be obtained using patient data in clinical practice. Therefore, in this study, we comprehensively analyzed datasets from JADER to clarify the tendency of AE occurrences and prognoses of nonbenzodiazepine hypnotic drugs in elderly patients.

Among the 28 AEs identified, the following 12 were particularly determined to require cautious monitoring in the elderly: glaucoma and ocular hypertension, 
Table 1 Comparison of signal values of elderly and non-elderly patients

\begin{tabular}{|c|c|c|c|c|c|c|c|c|c|}
\hline \multirow[t]{2}{*}{ adverse event (High Level Group Term) } & \multicolumn{4}{|c|}{ elderly patients (over the age of 60) } & \multicolumn{4}{|c|}{ non-elderly patients (under the age of 60) } & \multirow[b]{2}{*}{ risk Judgment } \\
\hline & $n_{11}$ & PRR & $x^{2}$ & signal value & $\mathrm{n}_{11}$ & PRR & $x^{2}$ & signal value & \\
\hline Deliria (include confusion) & 84 & 16.2 & 1079.4 & 9.8 & 34 & 12.0 & 304.3 & 8.2 & \\
\hline Product use issues & 14 & 40.0 & 391.1 & 9.7 & 31 & 23.0 & 536.5 & 9.4 & \\
\hline Sleep disturbances (include subtypes) & 26 & 14.9 & 294.4 & 8.4 & 14 & 6.8 & 60.9 & 6.0 & \\
\hline Sleep disturbances & 38 & 10.8 & 309.3 & 8.1 & 24 & 6.0 & 91.0 & 6.3 & \\
\hline Glaucoma and ocular hypertension & 10 & 21.3 & 152.6 & 8.1 & $0(0.5)$ & $0(1.6)$ & $0.1(0.3)$ & $-(-0.7)$ & $\times$ \\
\hline Psychiatric and behavioural symptoms NEC & 22 & 13.7 & 225.8 & 8.0 & 24 & 4.4 & 58.7 & 5.6 & \\
\hline Impulse control disorders NEC & 6 & 26.0 & 102.5 & 7.9 & $0(0.5)$ & $0(1.0)$ & $0.001(0.5)$ & $-(-0.7)$ & $\times$ \\
\hline Dementia and amnestic conditions & 21 & 10.0 & 152.3 & 7.3 & 13 & 14.4 & 134.5 & 7.6 & \\
\hline Suicidal and self-injurious behaviours NEC & 19 & 10.4 & 142.0 & 7.3 & 49 & 7.3 & 250.17 .5 & & \\
\hline Mental impairment disorders & 22 & 8.3 & 127.8 & 7.0 & 14 & 10.1 & 98.4 & 6.9 & \\
\hline Neurological disorders NEC & 153 & 3.6 & 294.5 & 7.0 & 103 & 3.6 & 194.7 & 6.5 & \\
\hline $\begin{array}{l}\text { Neurological special senses and psychiatric } \\
\text { investigations }\end{array}$ & 6 & 13.4 & 52.2 & 6.5 & 1 & 2.1 & 0.0007 & -6.5 & $\times$ \\
\hline Psychiatric disorders NEC & 39 & 4.0 & 83.1 & 5.8 & 50 & 6.1 & 203.1 & 7.1 & \\
\hline Respiratory disorders NEC & 51 & 2.9 & 60.8 & 5.2 & 35 & 2.7 & 36.1 & 4.6 & \\
\hline Injuries by physical agents & 7 & 6.4 & 25.6 & 5.1 & 2 & 1.2 & 0.0008 & -4.6 & $\times$ \\
\hline $\begin{array}{l}\text { Personality disorders and disturbances in } \\
\text { behavior }\end{array}$ & 5 & 7.6 & 21.3 & 5.1 & 3 & 1.9 & 0.6 & 0.1 & $\times$ \\
\hline Neurological disorders of the eye & 9 & 4.6 & 21.3 & 4.6 & 4 & 2.4 & 2.0 & 1.6 & $\times$ \\
\hline Injuries NEC & 35 & 2.6 & 33.0 & 4.5 & 17 & 2.6 & 15.4 & 3.7 & \\
\hline Changes in physical activity & 6 & 4.9 & 14.7 & 4.3 & 4 & 2.8 & 3.0 & 2.2 & \\
\hline $\begin{array}{l}\text { Manic and bipolar mood disorders and } \\
\text { disturbances }\end{array}$ & 3 & 6.7 & 9.0 & 4.1 & 2 & 1.2 & 0.02 & -3.8 & $x$ \\
\hline Movement disorders (include parkinsonism) & 21 & 2.7 & 19.9 & 4.0 & 12 & 1.6 & 2.1 & 1.2 & $\times$ \\
\hline Anxiety disorders and symptoms & 6 & 3.7 & 9.0 & 3.5 & 7 & 2.1 & 3.0 & 1.8 & \\
\hline $\begin{array}{l}\text { Therapeutic and nontherapeutic effects } \\
\text { (exclude toxicity) }\end{array}$ & 15 & 2.6 & 12.7 & 3.5 & 16 & 3.0 & 19.1 & 4.1 & \\
\hline Enzyme investigations NEC & 17 & 2.4 & 12.4 & 3.4 & 3 & 0.4 & 2.1 & -0.2 & $\times$ \\
\hline Disturbances in thinking and perception & 12 & 2.5 & 9.1 & 3.1 & 5 & 1.2 & 0.05 & -2.9 & $\times$ \\
\hline Vision disorders & 7 & 2.6 & 5.3 & 2.6 & 3 & 1.6 & 0.2 & -0.9 & $\times$ \\
\hline Ocular infections irritations and inflammations & 8 & 2.4 & 5.0 & 2.5 & $0(0.5)$ & $0(0.1)$ & $3.7(2.9)$ & $-(-1.2)$ & $\times$ \\
\hline Depressed mood disorders and disturbances & 5 & 2.8 & 4.1 & 2.4 & 6 & 2.5 & 3.9 & 2.3 & \\
\hline
\end{tabular}

$※ n_{11}$ the number of co-occurrences of interest, PRR proportional reporting ratio, signal value: $\ln (P R R)+\ln (x 2)$, risk judgment: low signal values of non-elderly patients than half of the signal value of the elderly, NEC not elsewhere classified

impulse control disorders NEC, neurological special senses and psychiatric investigations, injuries by physical agents, personality disorders and disturbances in behavior, neurological disorders of the eye, manic and bipolar mood disorders and disturbances, movement disorders (include parkinsonism), enzyme investigations NEC, disturbances in thinking and perception, vision disorders, and ocular infections irritations and inflammations. Regarding the manifestation of these AEs, medical personnel including pharmacists need to pay attention to elderly patients administered Z-drugs.
In this study, we found that following psychiatric disorders, AEs related to eye disorders were increasingly exhibited by the elderly. Among eye disorders, "blepharospasm", which is a local dystonia is a problem recently identified as an $\mathrm{AE}$ of benzodiazepines and Z-drugs. Blepharospasm is considered to cause diseases that induce strong sensory hypersensitivity and lead to eyelid loss.

Benzodiazepines and Z-drugs have been found to cause side effects that interfere with comfortable vision such as robust and persistent "dazzling," "pain," and "blurred vision." Wakakura et al. [17] have warned that these symptoms are likely "benzodiazepine induced blepharospasm". 
Table 2 Number and adverse event of signal detection included in SOC.

\begin{tabular}{|c|c|}
\hline $\begin{array}{l}\text { adverse event: SOC (Number of } \\
\text { HGLTs included in SOC) }\end{array}$ & adverse event: HGLT \\
\hline \multirow[t]{13}{*}{ Psychiatric disorders (13) } & Deliria (include confusion) \\
\hline & Sleep disturbances \\
\hline & $\begin{array}{l}\text { Psychiatric and behavioural } \\
\text { symptoms NEC }\end{array}$ \\
\hline & Impulse control disorders NEC \\
\hline & Dementia and amnestic conditions \\
\hline & $\begin{array}{l}\text { Suicidal and self-injurious } \\
\text { behaviours NEC }\end{array}$ \\
\hline & Psychiatric disorders NEC \\
\hline & $\begin{array}{l}\text { Personality disorders and } \\
\text { disturbances in behavior }\end{array}$ \\
\hline & Changes in physical activity \\
\hline & $\begin{array}{l}\text { Manic and bipolar mood disorders } \\
\text { and disturbances }\end{array}$ \\
\hline & Anxiety disorders and symptoms \\
\hline & $\begin{array}{l}\text { Disturbances in thinking and } \\
\text { perception }\end{array}$ \\
\hline & $\begin{array}{l}\text { Depressed mood disorders and } \\
\text { disturbances }\end{array}$ \\
\hline \multirow[t]{5}{*}{ Nervous system disorders (5) } & $\begin{array}{l}\text { Sleep disturbances (include } \\
\text { subtypes) }\end{array}$ \\
\hline & Mental impairment disorders \\
\hline & Neurological disorders NEC \\
\hline & Neurological disorders of the eye \\
\hline & $\begin{array}{l}\text { Movement disorders (include } \\
\text { parkinsonism) }\end{array}$ \\
\hline \multirow{3}{*}{$\begin{array}{l}\text { Movement disorders (include } \\
\text { parkinsonism) }\end{array}$} & Product use issues \\
\hline & Injuries by physical agents \\
\hline & Injuries NEC \\
\hline \multirow[t]{3}{*}{ Eye disorders (3) } & Glaucoma and ocular hypertension \\
\hline & Vision disorders \\
\hline & $\begin{array}{l}\text { Ocular infections irritations and } \\
\text { inflammations }\end{array}$ \\
\hline \multirow[t]{2}{*}{ Investigations (2) } & $\begin{array}{l}\text { Neurological special senses and } \\
\text { psychiatric investigations }\end{array}$ \\
\hline & Enzyme investigations NEC \\
\hline $\begin{array}{l}\text { Respiratory thoracic and } \\
\text { mediastinal disorders ( } 1 \text { ) }\end{array}$ & Respiratory disorders NEC \\
\hline $\begin{array}{l}\text { General disorders and } \\
\text { administration site conditions (1) }\end{array}$ & $\begin{array}{l}\text { Therapeutic and nontherapeutic } \\
\text { effects (exclude toxicity) }\end{array}$ \\
\hline
\end{tabular}

SOC System Organ Class, HLGT High Level Group Term, NEC not elsewhere classified

In "benzodiazepine induced blepharospasm," a few patients are aware of the dazzling, pain, and foggy feeling. However, in general ophthalmology, this disorder may be treated as dry eye or asthenopia, and patients may be considered nervous and fixated on their eyes, although
Table 3 Number and adverse event of signal detection in elderly risk included in SOC.

\begin{tabular}{|c|c|}
\hline $\begin{array}{l}\text { adverse event: SOC (Number of } \\
\text { HGLTs included in SOC) }\end{array}$ & adverse event: HGLT \\
\hline \multirow[t]{4}{*}{ Psychiatric disorders (4) } & Impulse control disorders NEC \\
\hline & $\begin{array}{l}\text { Personality disorders and } \\
\text { disturbances in behavior }\end{array}$ \\
\hline & $\begin{array}{l}\text { Manic and bipolar mood disorders } \\
\text { and disturbances }\end{array}$ \\
\hline & $\begin{array}{l}\text { Disturbances in thinking and } \\
\text { perception }\end{array}$ \\
\hline \multirow[t]{3}{*}{ Eye disorders (3) } & $\begin{array}{l}\text { Glaucoma and ocular } \\
\text { hypertension }\end{array}$ \\
\hline & Vision disorders \\
\hline & $\begin{array}{l}\text { Ocular infections irritations and } \\
\text { inflammations }\end{array}$ \\
\hline \multirow[t]{2}{*}{ Nervous system disorders (2) } & Neurological disorders of the eye \\
\hline & $\begin{array}{l}\text { Movement disorders (include } \\
\text { parkinsonism) }\end{array}$ \\
\hline \multirow[t]{2}{*}{ Investigations (2) } & $\begin{array}{l}\text { Neurological special senses and } \\
\text { psychiatric investigations }\end{array}$ \\
\hline & Enzyme investigations NEC \\
\hline $\begin{array}{l}\text { Injury poisoning and procedural } \\
\text { complications (1) }\end{array}$ & Injuries by physical agents \\
\hline
\end{tabular}

SOC System Organ Class, HLGT High Level Group Term, NEC not elsewhere classified

they are thought to be healthy. Therefore, it is also important for a pharmacist who has a wide knowledge of drugs to confirm these observations [18].

Analysis using spontaneous report databases such as the JADER used in this study could identify "AEs that are highly related to expression risk" and "AEs related to poor prognosis" in elderly patients. However, the spontaneous report database cannot provide the total number of patients using the target Z-drug. In addition, because the number of AEs registered does not correspond to the total number of patients who develop AEs, their incidence cannot be calculated. It should be noted that some AEs may be very rarely expressed despite their association with a higher risk of development in the elderly than in the non-elderly patients. Thus, there are certain limitations in analyzing the results of studies using data from spontaneously reporting databases, and further detailed clinical research would be required in the future. The WHO defines a safety signal as: is "Reported information on a possible causal relationship between an adverse event and a drug, the relationship being unknown or incompletely documented previously" [19], and it cannot be concluded simply by detecting a signal. However, those with large differences in signal values are characterized, and attention needs to be considered. In addition, in this 
Table 4 Comparison of prognosis of elderly and non-elderly patients

\begin{tabular}{|c|c|c|}
\hline Adverse event (High Level Group Term) & $\mathrm{RR}(95 \% \mathrm{Cl})$ & $x^{2}$ \\
\hline \multicolumn{3}{|c|}{ Especially the prognostic comparison of AEs characterized by the elderly } \\
\hline Glaucoma and ocular hypertension & $0.33(0.12-0.92)$ & 0.32 \\
\hline Impulse control disorders NEC & $0.08(0.01-1.10)$ & 0.09 \\
\hline Neurological special senses and psychiatric investigations & $1.00(1.00-1.00)$ & NA \\
\hline Injuries by physical agents & $0.33(0.01-12.81)$ & 0.37 \\
\hline Personality disorders and disturbances in behaviour & $1.91(0.10-34.92)$ & 0.13 \\
\hline Neurological disorders of the eye & $0.67(0.27-1.63)$ & 0.04 \\
\hline Manic and bipolar mood disorders and disturbances & $0.71(0.02-25.32)$ & 0.86 \\
\hline Movement disorders (include parkinsonism) & $0.35(0.04-3.46)$ & 0.10 \\
\hline Enzyme investigations NEC & $0.23(0.02-2.73)$ & 0.06 \\
\hline Disturbances in thinking and perception & $0.39(0.01-16.90)$ & 0.42 \\
\hline Vision disorders & $4.85(0.35-66.36)$ & 0.99 \\
\hline Ocular infections irritations and inflammations & $0.47(0.21-1.00)$ & 0.53 \\
\hline \multicolumn{3}{|l|}{ Prognostic comparison of other AEs } \\
\hline Deliria (include confusion) & $3.91(0.22-68.39)$ & 0.30 \\
\hline Product use issues & $0.67(0.09-4.83)$ & 0.02 \\
\hline Sleep disturbances (include subtypes) & $1.82(0.23-14.26)$ & 0.004 \\
\hline Sleep disturbances & $1.53(0.33-7.13)$ & 0.02 \\
\hline Psychiatric and behavioural symptoms NEC & $2.88(0.71-11.73)$ & 1.55 \\
\hline Dementia and amnestic conditions & $0.80(0.06-11.50)$ & 0.33 \\
\hline Suicidal and self-injurious behaviours NEC & $0.95(0.48-1.89)$ & 0.02 \\
\hline Mental impairment disorders & $0.87(0.06-12.52)$ & 0.40 \\
\hline Neurological disorders NEC & $1.18(0.47-2.91)$ & 0.01 \\
\hline Psychiatric disorders NEC & $0.31(0.04-2.65)$ & 0.46 \\
\hline Respiratory disorders NEC & $0.48(0.27-0.87)$ & 5.54 \\
\hline Injuries NEC & $1.20(0.37-3.93)$ & 0.01 \\
\hline Changes in physical activity & $0.80(0.07-9.18)$ & 0.39 \\
\hline Changes in physical activity & $0.80(0.07-9.18)$ & 0.39 \\
\hline Therapeutic and nontherapeutic effects (exclude toxicity) & $0.44(0.02-9.61)$ & 0.04 \\
\hline Depressed mood disorders and disturbances & $1.5(0.13-17.67)$ & 0.23 \\
\hline
\end{tabular}

※AEs adverse events, RR risk ratio, $95 \% \mathrm{Cl} 95 \%$ confidence interval, NEC not elsewhere classified

study, there were some AEs with few differences, but further investigation is necessary due to future accumulation of case reports.

\section{Conclusions}

In this study, in addition to movement disorders such as "falls" and "bone fractures" recorded by "THE JAPANESE SOCIETY OF SLEEP RESEARCH" and "THE JAPAN GERIATRIC SOCIETY," signals that are characteristic to the elderly were obtained for psychiatric disorders and eye disorders. These disorders are possible irreversible progressions of symptoms and could reduce the quality of life of patients. However, as they are concerned about in the report, eye disorders caused by benzodiazepine receptor agonists in Japan are not recognized as important adverse events in Japan. This study is a comprehensive analysis of adverse events, and more detailed analysis is required. However, in addition to each clinical practice guideline, attention must be paid to the manifestation of AEs caused by Z-drugs revealed in this study until more detailed analysis results are obtained.

We consider that appropriate drug therapy for insomnia should be implemented by practicing side effect management. This would include considering individual patients and paying attention to the occurrence of Z-drug-induced AEs revealed in this study and the guidelines of each academic society. And we believe that this paper will contribute to future detailed side effects studies and proper use of Z-drugs. 


\section{Abbreviations}

AE: Adverse event; BCPNN: Bayesian confidence propagation neural network; BZ: Benzodiazepine; Cl: Confidence interval; CNS: Central nervous system; GABA: Gamma-aminobutyric acid; GPS: Gamma-Poisson Shrinker; GRADE: Grading of recommendations assessment, development, and evaluation; HLGT: High-level group term; JADER: Japanese adverse drug event report database; MedDRA/J: Medical dictionary for regulatory activities/ Japanese version; NEC: Not elsewhere classified; PRR: Proportional reporting ratio; PT: Preferred term; ROR: Reporting odds ratio; RR: Risk ratio; SOC: System organ class; SRS: Spontaneous reporting system; WHO: World Health Organization; Z-drug: Non-benzodiazepine

\section{Funding}

This study was carried out with the aid of JSPS scientific research fund 16 K19175 and subsidy of the Health Care Science Institute.

\section{Availability of data and materials}

Data are owned by the Japanese Adverse Drug Event Report database (JADER) suppliedfrom PMDA can be accessed directly here: http://www.info.pmda.go.jp/fukusayoudb/CsvDownload.jsp (only in Japanese).

Authors do not own the data because PMDA in the Japanese authority, does not permit sharing them directly.

\section{Authors' contributions}

Conceived and designed the experiments: YN, TTsuchiya, HT. Performed the experiments: YN, AU, HK, MO. Analyzed the data: YN, AY, YK, IS. Contributed reagents/materials/analysis tools: $Y N$, TTachi, $H T$. Wrote the paper: $Y N$, $H T$. All authors read and approved the final manuscript.

\section{Ethics approval and consent to participate}

Not applicable.

\section{Competing interests}

Although Laboratory of Community Healthcare Pharmacy, Gifu Pharmaceutical University, is financially supported by donations from WELCIA YAKKYOKU CO., LTD., the authors report no conflicts of interest regarding the content of this article.

\section{Publisher's Note}

Springer Nature remains neutral with regard to jurisdictional claims in published maps and institutional affiliations.

\section{Author details}

'Laboratory of Clinical Pharmacy, Gifu Pharmaceutical University, 1-25-4, Daigakunishi, Gifu 501-1196, Japan. ${ }^{2}$ Community Health Support and Research Center, 5-6-1, kikuchichou, Gifu 501-6242, Japan. ${ }^{3}$ Laboratory of Community Healthcare Pharmacy, Gifu Pharmaceutical University, 1-25-4, Daigakunishi, Gifu 501-1196, Japan.

Received: 14 January 2018 Accepted: 3 April 2018

Published online: 07 May 2018

\section{References}

1. Kim K, Uchiyama M, Okawa M, Liu X, Ogihara R. An epidemiological study of insomnia among the Japanese general population. Sleep. 2000;23:41-7.

2. Doi Y, Minowa M, Okawa M, Uchiyama M. Prevalence of sleep disturbance and hypnotic medication use in relation to sociodemographic factors in the general Japanese adult population. J Epidemiol. 2000;10:79-86.

3. Okumura Y. Psychotropic medicine use that may be inappropriate from clinical epidemiological research:4 points to keep in mind. Monthly IHEP. 2016;249:21-9

4. Fujita T. Signal detection of adverse drug reactions, Jpn. J Pharmacoepidemiol. 2009;14:27-36.

5. Fujimoto M, Hosomi K, Takada M. Statin-associated lower urinary tract symptoms: data mining of the public version of the FDA adverse event reporting system, FAERS. Int J Clin. Pharmacol Ther. 2014;52:259-66.

6. Hata T, Hamada T, Suzuki K, Katsumata T. Analysis of gender and age dependent weight gain related to antipsychotic drugs by data Mining of the Japanese Adverse Drug Event Report Database (JADER). J Jpn Soc Hosp Pharm. 2015;51:411-5.
7. Noguchi Y, Esaki H, Asano S, Yokoi T, Usui K, Kato M, et al. Analysis of effects of the diuretics on levels of blood potassium and blood sodium with angiotensin receptor blockers and thiazide diuretics combination therapy: data Mining of the Japanese Adverse Drug Event Report Database, JADER. Jpn J Pharm Health Care Sci. 2015;41:488-96.

8. Noguchi Y, Saito K, Esaki H, Usui K, Kato M, Tachi T, et al. Examination for safety of antiplatelet therapy in the elderly patients using data Mining of the Japanese Adverse Drug Event Report (JADER) database. Jpn J Drug Inform. 2016;17:192-8.

9. Evans SJ, Waller PC, Davis S. Use of proportional reporting ratios (PRRs) for signal generation from spontaneous adverse drug reaction reports. Pharmacoepidemiol Drug Saf. 2001;10:483-6.

10. Rothman KJ, Lanes S, Sacks ST. The reporting odds ratio and its advantages over the proportional reporting ratio. Pharmacoepidemiol Drug Saf. 2004;13:519-23.

11. Bate $A$, Lindquist $M$, Edwards IR, Olsson S, Orre R, Lansner A, et al. A Bayesian neural network method for adverse drug reaction signal generation. Eur J Clin Pharmacol. 1998;54:315-21.

12. Szarfman A, Machado SG, O'Neill RT. Use of screening algorithms and computer systems to efficiently signal higher-than-expected combinations of drugs and events in the US FDA's spontaneous reports database. Drug Saf. 2002;25:381-92.

13. Noguchi Y, Hayashi Y, Yoshida A, Sugita I, Esaki H, Saito K, et al. Search for oral medicine that might exacerbate the prognosis of adverse drug events in elderly patients. Jpn J Drug Inform. 2016;18:277-83.

14. Noguchi Y, Hayashi Y, Yoshida A, Sugita I, Esaki H, Saito K, et al. Pharmacoepidemiological examination for the safety of the oral laxatives in the elderly patients. Jpn J Drug Inform. 2016;18:179-85.

15. Shirakuni Y, Okamoto K, Kawashita N, Yasunaga T, Takagi T. Signal detection of drug complications applying association rule learning for StevensJohnson syndrome. J Com Aid Chem. 2009;10:118-27.

16. Watanabe $H$, Matsushita $Y$, Watanabe A, Maeda T, Nukui K, Ogawa $Y$, et al. Early detection of important safety information. Jpn J Biomet. 2004;25:37-60.

17. Wakakura M, Tsubouchi T, Inouye J. Etizolam and benzodiazepine induced blepharospasm. J Neurol Neurosurg Psychiatry. 2004;75:506-7.

18. Emoto $Y$, Emoto H, Oishi E, Hikita S, Wakakura M. Twelve cases of drug-induced blepharospasm improved within 2 months of psychotropic cessation. Drug Healthc Patient Saf. 2011;3:9-14.

19. Edwards $I R$, Lindquist $M$, Wiholm BE, Napke E. Quality criteria for early signals of possible adverse drug reactions. Lancet. 1990;336:156-8.

\section{Ready to submit your research? Choose BMC and benefit from:}

- fast, convenient online submission

- thorough peer review by experienced researchers in your field

- rapid publication on acceptance

- support for research data, including large and complex data types

- gold Open Access which fosters wider collaboration and increased citations

- maximum visibility for your research: over $100 \mathrm{M}$ website views per year

At BMC, research is always in progress.

Learn more biomedcentral.com/submissions 